$\beta_{2}-1123$

ANCR-1171

UC - 37

\title{
THE APPLICATION OF A REAL TIME STACK MONITOR USING A Ge(Li) DETECTOR AND A PDP-9 PROCESSOR
}

\author{
E. B. Nieschmidt \\ N. C. Dyer
}

E. W. Killian

R. A. Coates

\section{Aerojet nuclear Company}

IDAHO NATIONAL ENGINEERING LABORATORY

Idaho Falls, Idaho - 83401

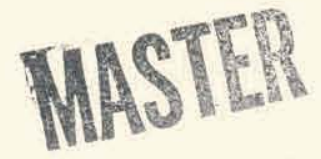

DATE PUBLISHED - NOVEMBER 1974

PREPARED FOR THE

\section{U. S. ATOMIC ENERGY COMMISSION}

IDAHO OPERATIONS OFFICE UNDER CONTRACT AT(10-1)-1375 


\section{DISCLAIMER}

This report was prepared as an account of work sponsored by an agency of the United States Government. Neither the United States Government nor any agency Thereof, nor any of their employees, makes any warranty, express or implied, or assumes any legal liability or responsibility for the accuracy, completeness, or usefulness of any information, apparatus, product, or process disclosed, or represents that its use would not infringe privately owned rights. Reference herein to any specific commercial product, process, or service by trade name, trademark, manufacturer, or otherwise does not necessarily constitute or imply its endorsement, recommendation, or favoring by the United States Government or any agency thereof. The views and opinions of authors expressed herein do not necessarily state or reflect those of the United States Government or any agency thereof. 


\section{DISCLAIMER}

Portions of this document may be illegible in electronic image products. Images are produced from the best available original document. 
Printed in the United States of America Avallable from

National Technical Information Service

U. S. Department of Commerce

5285 Port Royal Road

Springfield, Virginia 22161

Price: Printed Copy $\$ 4.00$; Microfiche $\$ 2.25$

\section{LEGAL NOTICE}

This report was prepared as an account of work sponsored by the United States Government. Neither the United States nor the United States Atomic Energy Commission, nor any of their employees, nor any of their contractors, subcontractors, or their employees, makes any warranty, express or implied, or assumes any legai liability or responsibility for the accuracy, completeness or usefulness of any information, apparatus, product or prociess disclosed, or represents that its use would not infringe privately owned rights. 


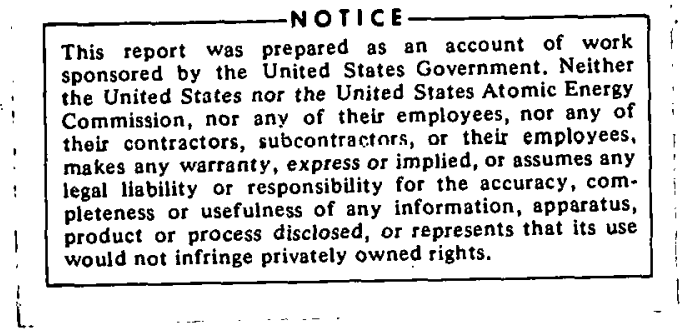

E. B. Nieschmidt

N. C. Dyer

E. W. Killian

R. A. Coates

AEROJET NUCLEAR COMPANY

Date Published - November 1974

Prepared for the U.S. Atomic Energy Commission

Idaho Operations office

Under Contract No. AT(10-1)-1375. 
ABSTRACT

The growing number of nuclear reactors used for power generation has increased the need for rapid isotopic analysis of reactor system effluents. Described here is a prototype stack monitor recently operated at the Advanced Test Reactor at the Idaho National Engineering Laboratory. This remotely operated system uses a $45 \mathrm{~cm}^{3} \mathrm{Ge}$ (Li) detector and a 4096. channel multi-channel analyzer; dața are processed by a PDP-9 computer. Data transmission and analyzer control is via commercial. telephone. and MODEM system.

During. a recent two week operating cycle the stack effluent was monitored. The more prominent isotopes observed include ${ }^{88} \mathrm{Kr}$, ${ }^{89} \mathrm{Kr},{ }^{89} \mathrm{Rb},{ }^{135} \mathrm{Xe}$ and ${ }^{138} \mathrm{Xe}$; numerous: other isotopes were identified and quantified. The results of this monitoring, interpretation of the data' and system operation will be 'discussed.. 
ABSTRACT . . . . . . . . . . . . . . . . . . . $i i$

1.0 INTRODUCTION . . . . . . . . . . . . . . . . . 1

2.0 REACTOR DESCRIPTION . . . . . . . . . . . . . . . 1

3.0 MONITOR DESCRIPTION . . . . . . . . . . . . . . . . 1

3.1 Spectrometer . . . . . . . . . . . . . . 1

3.2 Analyzer Control .. . . . . . . . . . . . . . 2

3.3 Transmission . . . . . . . . . . . . 2

3.4 PDP-9 Control Processor ............ 2

4.0 DATA ACCUMULATION . . . . . . . . . . . . . 3

5.0 TREATMENT OF DATA . . . . . . . . . . . . . . . . 3

5.1 Search ................... . 3.

5.2 Fits................... . . 3

5.3 Energies and Intensities............. 4

5.4 Library Search . . . . . . . . . . . . . . 5

5.5 Subsequent Calculations ............ 5

6.0 RESULTS . . . . . . . . . . . . . . . 6

6.1 Sensitivity . . . . . . . . . . . . 6

6.2 Limitations .............. . 8

7.0 DISCUSSION AND FUTURE PLANS . . . . . . . . . . . . . . 9

7.1 Additional Information Available . . . . . . . 9

7.2 Future Plans............... 10

8.0 REFERENCES .................... 11

LIST OF TABLES

Table I , 1.91 yr. ${ }^{228}$ Th Calibration Energies ...... 4

Table II Gas Sample Calibration Gamma-Rays . . . . . . 5

Table III Radioisotopes Considered in This Study . . . . . 7

\section{LIST OF FIGURES}

Figure 1. Stack Monitor System Block Diagram . . . . . . 12

Figure 2. Gamma-ray spectrom from the ATR stack effluent. . . 13

Figure 3. Block Diagram of Data Treatment . . . . . . . . 14 
Figure 4. Release of ${ }^{41} \mathrm{Ar}$ during ATR cycle $19 \mathrm{~A} .{ }^{41} \mathrm{Ar}$ is not a fission product but is produced by neutron activation.

Figure 5. Release of $85 \mathrm{~m}_{\mathrm{Kr}}$ and ${ }^{87} \mathrm{Kr}$ during ATR cycle $19 \mathrm{~A} .{ }^{85} \mathrm{~m}_{\mathrm{Kr}}$ and ${ }^{87} \mathrm{Kr}$ arc both fission products. . . . . . .

Figure 6. Release of ${ }^{88} \mathrm{Kr}$ and ${ }^{88} \mathrm{Rb}$ during ATR cycle $19 \mathrm{~A} .{ }^{88} \mathrm{Kr}$ and ${ }^{88} \mathrm{Rb}$ are both fission products. . . . . . .

Figure 7. Release of ${ }^{89} \mathrm{Kr}$ and ${ }^{89} \mathrm{Rb}$ during ATR cycle $19 \mathrm{~A} .{ }^{89} \mathrm{Kr}$ and ${ }^{89} \mathrm{Rb}$ are both fission products. . . . . . . .

Figure 8. Release of ${ }^{137} \mathrm{Xe}$ during ATR cycle 19.A. ${ }^{137} \mathrm{Xe}$ is a fission product. All $137 \mathrm{Xe}$ released ultimately becomes environmental ${ }^{137} \mathrm{Cs} . . . . . . . . .$.

Figure 9. Release of ${ }^{138} \mathrm{Xe}$ and ${ }^{138} \mathrm{Cs}$ during ATR cycle 19A: $138 \mathrm{Xe}$ and ${ }^{138} \mathrm{Cs}$ are both fission products..... 


\subsection{INTRODUCTION}

Described here is a prototype stack monitor installed at the Advanced Test Reactor (ATR) and operated for two cycles. This device measures directly the concentration of gamma-ray emitting isotopes in the stack effluent stream. This is accomplished by use of high resolution $\mathrm{Ge}(\mathrm{L} i)$ gamma-ray spectrometry and the subsequent processing of data by computer. The control and operation of the system is accomplished by a remote computer with transmission of data and control information over commercial.grade telephone lines.

The monitoring of effluents from nuclear plants using high resolution gamma-ray spectrometry has been discussed by Heath and Cline ${ }^{(1)}$. The discussion here applies only to the system used at the ATR stack.

\subsection{REACTOR DESCRIPTION}

The ATR is a light water cooled high flux test reactor with nominal operating power of $250 \mathrm{MW}$. The gas flow through the stack system is approximately $50,000 \mathrm{cfm}$. The stack system exhausts the experimental loops as well as the reactor itself.

\subsection{MONITOR DESCRIPTION}

Shown in Figure 1 is a block diagram of the system used for the stack monitoring system. The system consists of four functional units.

\subsection{Spectrometer}

The high resolution spectrometer consists of a Ge(Li) gamma-ray detector and associated pre-amplifier, a linear pulse amplifier, a 
4096 channel pulse height analyzer and an 8 word multiplexer unit. Gamma rays emitted by the decay of radionuclides in the stack gas are detected by the $\mathrm{Ge}(\mathrm{Li})$ detector. This pulse height information is accumulated and stored in the memory of the multi-channel analyzer. The multiplexer supplies the rest of the system with the analyzer output data and the analyzer status.

\subsection{Analyzer Control}

Analyzer control is performed through a hardwired interface which receives and interprets digital commands from the master computer. Some of the functions performed by the interface include:
(1) Clear analyzer memory
(2) Set live timer
(3) Start analyzer
(4) Stop analyzer
(5) Transmit data
(6) Transmit analyzer status.

\subsection{Transmission}

Communication between the master computer and the analyzer interface is accomplished over commercial phone lines using asynchronous, serial, half-duplex, 1200 baud commercial MODEMs. The analyzer interface contains logic to perform automatic answer and will disconnect from the line upon command from the host computer.

\subsection{PDP-9 Control Processor}

The control processor unit and associated software is the basis of the remote monitoring system. The processor unit operates with the GAP-XVI system, a series of programs written for the PDP-9 and arranged 
in a convenient modular fashion. The individual routines are switch selectable on one large control panel. The control panel has the appearance of a hardwired analysis system.

\subsection{DATA ACCUMULATION}

A total of 28 monitor produced gamma-ray spectra were accumulated during the first cycle and 56 during the second cycle. Spectra were accumulated typically for $1000 \mathrm{sec}$ or one hour although one was a $17,000 \mathrm{sec}$ run to examine very low level activities.

\subsection{TREATMENT OF DATA}

Figure 2 shows a spectrum of gamma-rays obtained from the ATR stack during cycle 19A. This is the graphical representation of data accumulated by the remote analyzer and transmitted via telephone to the PDP-9. The subsequent treatment of the data is outlined in Figure 3. A complete discussion of the mechanics of data treatment has been given by Helmer, Putnam and Cline (References 2 and 3 ).

\subsection{Search}

The first step in data reduction consists of a search of the spectrum with a cross-correlation routine which detects the presence of significant gamma-ray peaks in the data. The result of this step is a file of the approximate channel numbers where peaks are located.

\subsection{Fits}

In this step, Gaussian functions are fit to the gamma-ray data, backgrounds determined and peak areas calculated. Also calculated in this step are uncertainties in peak areas and peak positions. 


\subsection{Energies and Intensities}

Measured detector efficiency is used to calculate gamma ray intensities from peak areas: Also in this analysis step measured deviations from linearity of the spectrometer are used to modify peak positions for more accurate energy determinations. Gamma ray energies and uncertainties are also calculated in this step.

Energy scale determinations for the monitor data used in these studies were established in the following manner. Prior to the first data accumulation a spectrum was accumulated using a ${ }^{228} \mathrm{Th}$ source. The $2614 \mathrm{keV}$ gamma-ray peak was.placed in the region of channel 2500 . This assured that the higher energy ( $\sim 4 \mathrm{MeV}$ ) gamma-rays of short lived fission gases and their daughters would be detected. The ${ }^{228} \mathrm{Th}$ gammaray energies used for calibration are given in Table I.

\section{Table I}

$1.91 \mathrm{yr} .{ }^{228} \mathrm{Th}$ Calibration Energies

$$
\begin{aligned}
& 238.614 \pm 0.009 \mathrm{keV}\left({ }^{212} \mathrm{~Pb}\right) \\
& 583.174 \pm 0.013 \mathrm{keV}\left({ }^{208} \mathrm{~T} 1\right) \\
& 860.53 \pm 0.05 \mathrm{keV}\left({ }^{208} \mathrm{~T} 1\right) \\
& 1620.70 \pm 0.10 \mathrm{keV}\left({ }^{212} \mathrm{Bi}\right) \\
& 2614.476 \pm 0.100 \mathrm{keV}\left({ }^{208} \mathrm{~T} 1\right)
\end{aligned}
$$

The thorium calibration was then used to establish the presence of gamma-rays of well known energies in the same sample. The calibration was then re-established using gamma-rays from the sample itself. Gamma-ray energies used and their origins are given in Table II. 


\section{$\underline{\text { Table II }}$}

\section{Gas Sample Calibration Gamma-Rays}

$$
\begin{array}{cc}
249.738 \pm 0.012 \mathrm{keV} & { }^{135} \mathrm{Xe} \\
462.790 \pm 0.028 \mathrm{keV} & 138 \mathrm{Cs} \\
1009.64 \pm 0.03 \mathrm{keV} & { }^{138} \mathrm{Cs} \\
1293.491 \pm 0.050 \mathrm{keV} & { }^{41} \mathrm{Ar} \\
1435.791 \pm 0.040 \mathrm{keV} & 138 \mathrm{Cs} \\
2217.74 \pm 0.08 \mathrm{keV} & 138 \mathrm{Cs} \\
2639.09 \pm 0.12 \mathrm{keV} & 138 \mathrm{Cs} \\
2753.92 \pm 0.10 \mathrm{keV} & { }^{24} \mathrm{Na}
\end{array}
$$

\subsection{Library Search}

Gamma-ray energies as calculated are compared with a library of gamma-rays associated with various radioisotopes. If an energy lies within a predetermined amount of a listed energy, an identification is made.

\subsection{Subsequent Calculations}

After isotopic assignment is made, the results of all the previous calculations are corrected for decay during transit, the volume of gas sampled, and losses because of analyzer dead time, and gamma ray branching ratio. 


\subsection{RESULTS}

The results of the stack monitor operation are shown in Figures 4 through 9. These present the release rate of the more prominent fission gases and their daughters as a function of time into the respective reactor cycle. Also shown are the power level histories and ${ }^{41} \mathrm{Ar}$ release rates for the two cycles. Table III lists the energy of gamma-rays used for the pertinent calculations for each isotope, its half-life and branching ratio and thermal fission yield. Fission yield stated is that of the fission gas and all short lived precursors (Reference 4). Only one gamma ray was chosen to represent each radioactivity; it had to have a well known energy, well measured branching ratio and be definitive of that isotope. This was usually, but not necessarily, the most intense transition in the decay. The results as presented are release rates in terms of the ${ }^{41} \mathrm{Ar}$ release rate. Only radioisotopes definitely known to be in the stack effluent have been considered. Some of the gamma-ray peaks in. Figure 2 are from other sources, ${ }^{228}$ Th from the concrete walls, and other soluble species in process water pipes located in the same room in which the monitor was located.

\subsection{Sensitivity}

The ability of the remote analyzer system to detect the presence of a radioisotope depended on a number of factors. The concentration of the radionuclide, its gamma-ray branching ratio, the energy of its radiation and the presence of the radiations from the other nuclides are the most important. A radionuclide with a gamma-ray of energy less than $\approx 1 \mathrm{MeV}$ and branching ratio of $100 \%$ can be reliably detected ( $(95 \%$ confidence) and its area measured within $20 \%$ if its abundance 


\section{Table III}

Radioisotopes Considered in This Study

Isotope

\begin{tabular}{c} 
Energy \\
$\mathrm{E}_{\mathrm{r}} \quad(\mathrm{keV})$ \\
\hline
\end{tabular}

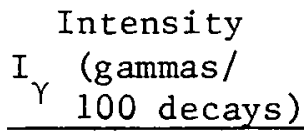

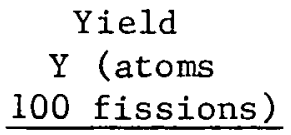

Half Life

${ }^{41} \mathrm{Ar}$

1293.49

99

0

$\mathrm{T}_{\frac{1}{2}}$ (hrs)

$85^{m_{\mathrm{Kr}}}$

151.07

75

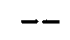

1.83

${ }^{87} \mathrm{Kr}$

402.578

53

2.5

4.48

$88 \mathrm{Kr}$

2392.02

38

3.5

1. 27

$89 \mathrm{Kr}$

858.90

21

4.6

2.80

${ }^{88} \mathrm{Rb}$

1836.017

23

$-$

0.053

${ }^{89} \mathrm{Rb}$

1031.94

65.4

--

0.29

$135 \mathrm{~m}_{\mathrm{Xe}}$

526.62

80

$-$

0.257

$135 \mathrm{Xe}$

249.74

90.7

6.4

0.26

$137 \mathrm{Xe}$

455.38

33

6.0

9.14

$138 \mathrm{Xe}$

258.

32

6.4

0.06

$138 \mathrm{Cs}$

1435.79

75.6

$-$

0.236

0.54 
is $\sim 1 \%{ }^{41} \mathrm{Ar}$ abundance. These numbers refer to $1000 \mathrm{sec}$ accumulation time. Lower abundance or branching ratios require longer data accumulation.

\subsection{Limitations}

Nuclear species which have no gamma-ray associated with their decay cannot be detected, the most important example being 90 . Sr. However, other $\mathrm{Sr}$ isotopes do emit gamma-rays in their decay. Isolupes of the same chemical species would be expected to behave identically in a reactor system.

When discussing this limitation, one must also consider that of 294 nuclear species produced in the slow. neutron fission of ${ }^{.23}{ }^{\circ} \mathrm{U}$ with mass chain yield $>1 \%$ and half lives $>-5$ sec., 226 or: $77 \%$ have gamma-rays with energies" $>50 \mathrm{keV}$ which could conceivably be used for identification and quantification. Others have gamma radiation associated with their decays, but have not been sufficiently studied to be definitive. The use of nuclear radiations other than gamma radiation. must be. discounted for use in real time monitoring. Beta rays from nuclear decay are not definitive because of their continuous energy distribution and the extreme difficulty associated with the measurement of end point energies. Neutrons from delayed neutron emitters are not definitive: and only a few fission product nuclides are neutron emitters. 


\subsection{DISCUSSION AND FUTURE PLANS}

\subsection{Additional Information Available}

The data required for routine effluent monitoring are available on an isotopic real time basis with a high degree of precision. In addition much information is obtained concerning the environmental accumulation of longer lived. radionuclides... ${ }^{137} \mathrm{Cs}$, being water soluble in most chemical compounds, is not released to any significant degree via the stack system. However, the presence of and release of ${ }^{137} \mathrm{Xe}$ (Figure 8) is monitored. Al1 ${ }^{137} \mathrm{Xe}$ which is released becomes environmental ${ }^{137} \mathrm{Cs}$. A similar situation exists with the decay chain

$$
90 \mathrm{Kr} \stackrel{\beta^{-}}{\longrightarrow}{ }^{90} \mathrm{Rb} \stackrel{\beta^{-}}{\longrightarrow} 9{ }^{90} \mathrm{Sr} .
$$

All of the ${ }^{90} \mathrm{Kr}$ and ${ }^{90} \mathrm{Rb}$ released eventually becomes environmental ${ }^{90} \mathrm{Sr}$. An inspection of the results presented here will demonstrate that these data may be used for purposes other than routine effluent statements. Figure 4 shows the constancy of the ${ }^{41} \mathrm{Ar}$ release rate at constant reactor power level. This is expected since the production of ${ }^{41}$ Ar, which is an activation product, is dependent only on the neutron flux level and the concentration of argon in the reactor coolant (after ${ }^{41} \mathrm{Ar}$ radioactivity has reached equilibrium and the coolant temperature has stabilized). The release rate of fission gases from the coolant should also be constant with constant reactor power level. Examination of Figures 5-9 indicate that for cycle 19A this was not true. All fission gas release rates increased with time from $\sim 300$ hours into the cycle until the end of the cycle. This is believed to be indicative of an incipient fission break in the ATR fuel which was detected in the next cycle by the fission break monitor. 
This example indicates how isotopic monitoring can be used for reactor systems diagnostics as well as effluent information. The ratio of ${ }^{41} \mathrm{Ar}$ release rate and fission gas release rates at constant power level and reactor temperature levels yields information about the fuel cladding condition. The ratio of krypton to xenon release rates yield additional information pertaining to the size of the cladding violations. This effect has been studied in $\mathrm{UO}_{2}$ fuels by R. F. S. Robertson, Reference 5 .

\subsection{Future Plans}

The computer programming required for unattended operation of the remote systems has been initiated and will be incorporated into future use of these systems. For system pulse height calibration, a precision pulser is being designed so that remote energy calibration can be accomplished. 


\subsection{REFERENCES}

1. R. L. Heath and J. E. Cline, IEEE Trans. Nucl. Sci. NS.-20, 65-72 (1973).

2. R. G. Helmer, M. H. Putnam, Gauss V, A Computer Program for the Analysis of Gamma-Ray Spectrum From Ge(Li) Spectrometers, ANCR1043 (1972).

3. J. E. Cline, M. H. Putnam and R. G. Helmer, Gauss VI, A Computer Program for the Automatic Batch Analysis of Gamma-Ray Spectra from Ge(I.i) Spectrometers, ANCR-1113 (1973).

4. A. Tobias, Data for the Calculation of Gamma Radiation Spectra and Beta Heating from Fission Products, RD/B/M2669, CNDC (7.3) p. 4 (June 1973).

5. R. F. S. Robertson, Tests of Defected Thoria-Urania:Fuel Specimens in EBWR, ANL-6022 (1960). 


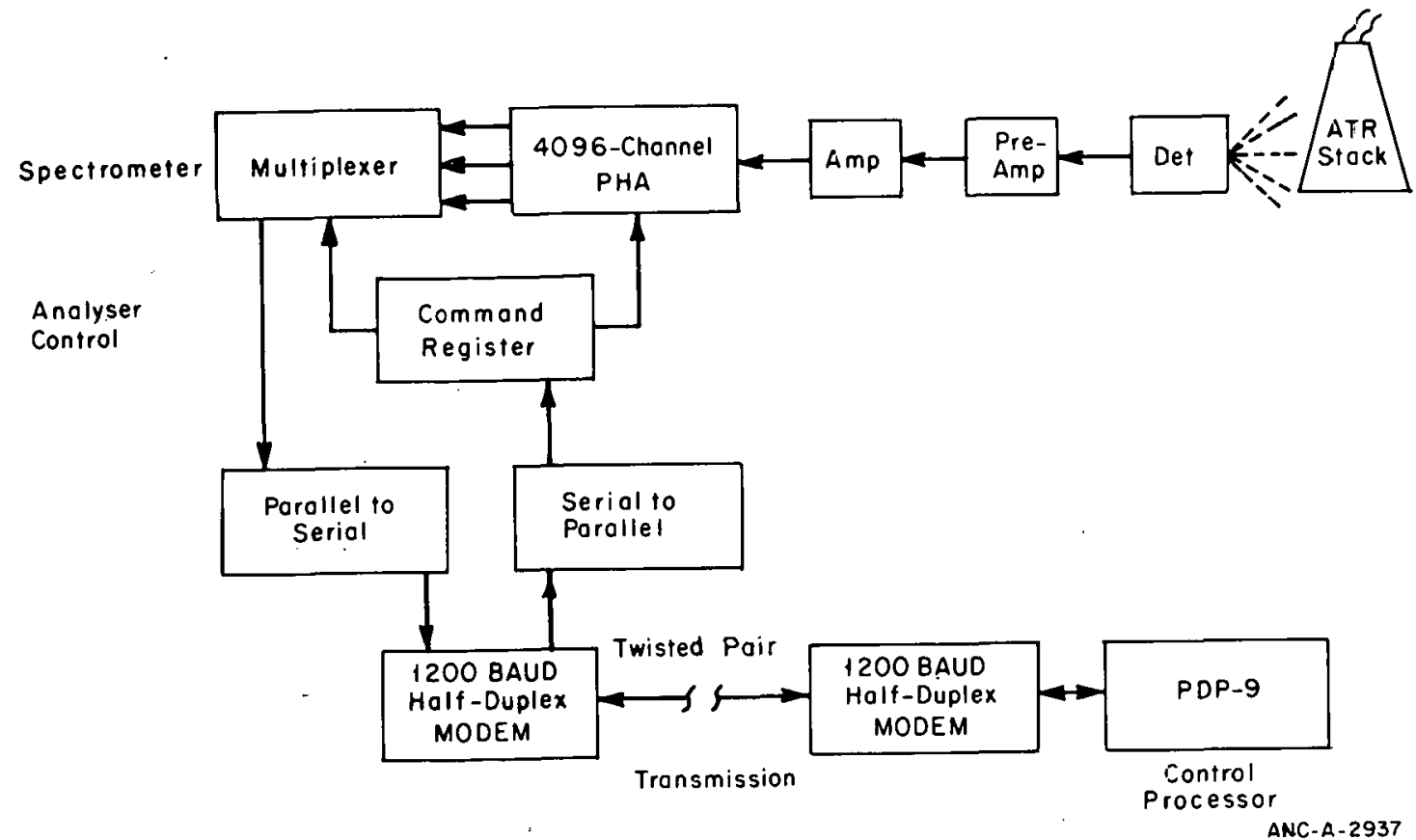

Figure 1. Stack Monitor System Block viagram 


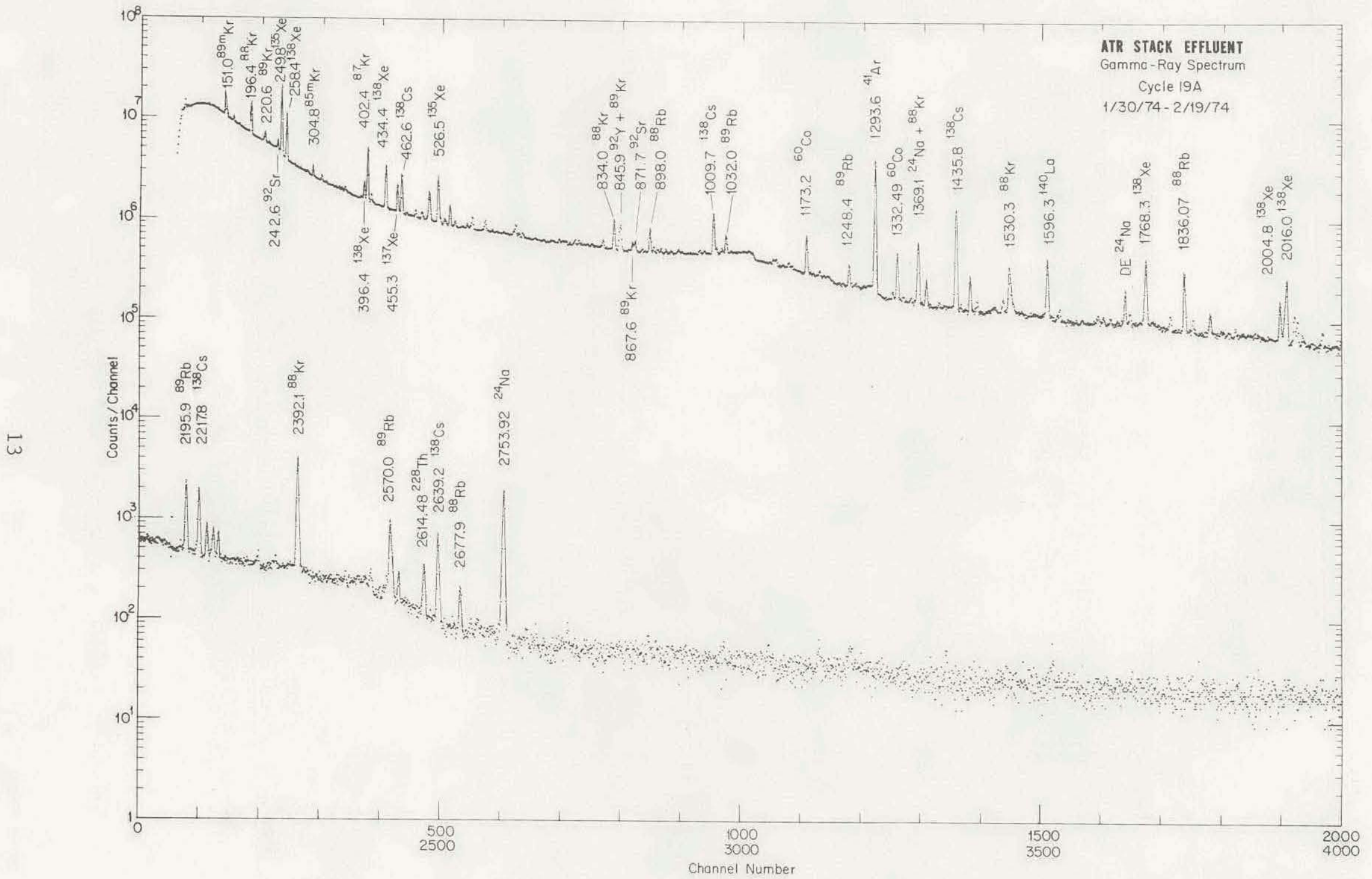

Figure 2. Gamma-ray spectrum from the ATR stack effluent. 


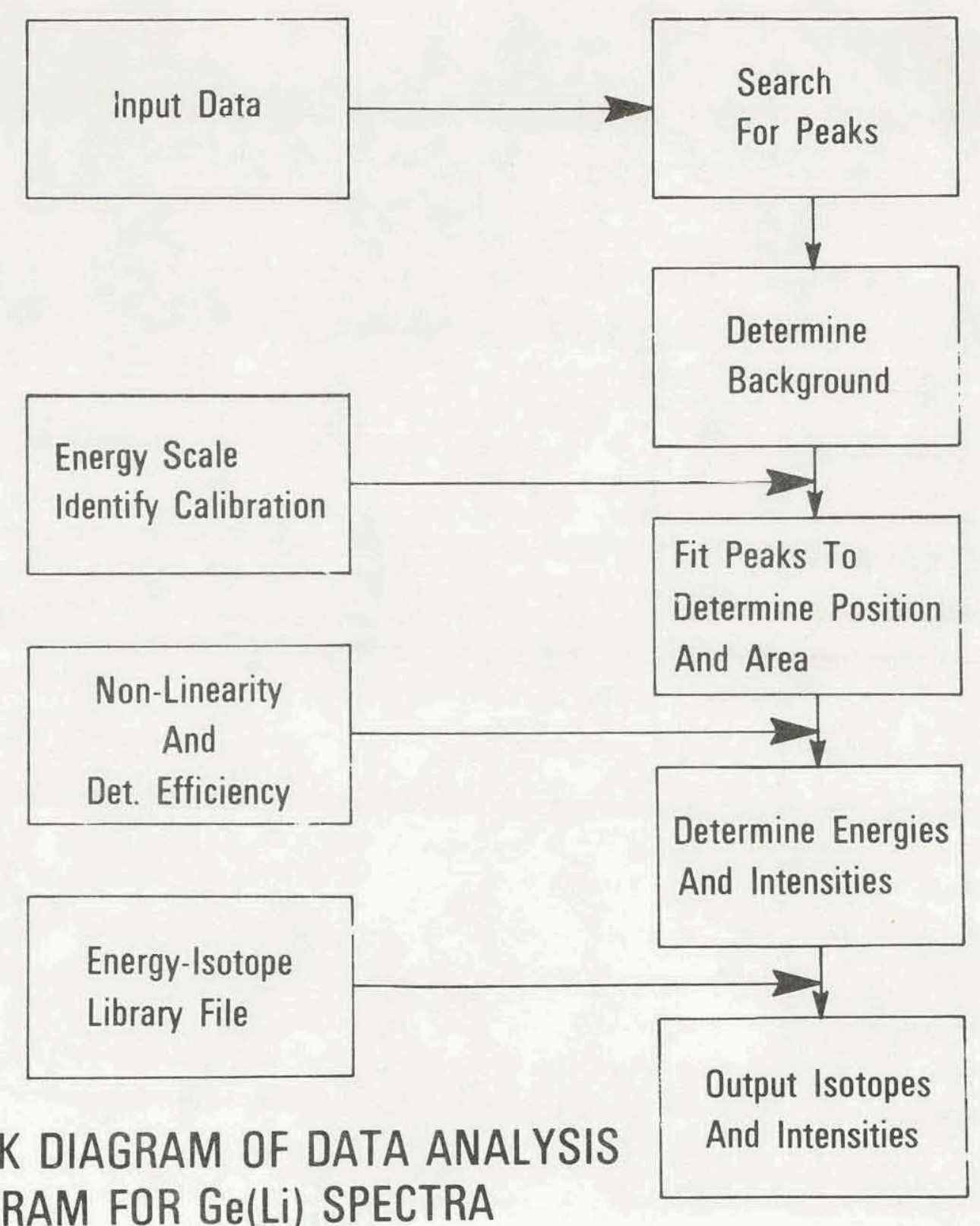
PROGRAM FOR Ge(Li) SPECTRA

Figure 3. Block Diagram of Data Treatment 


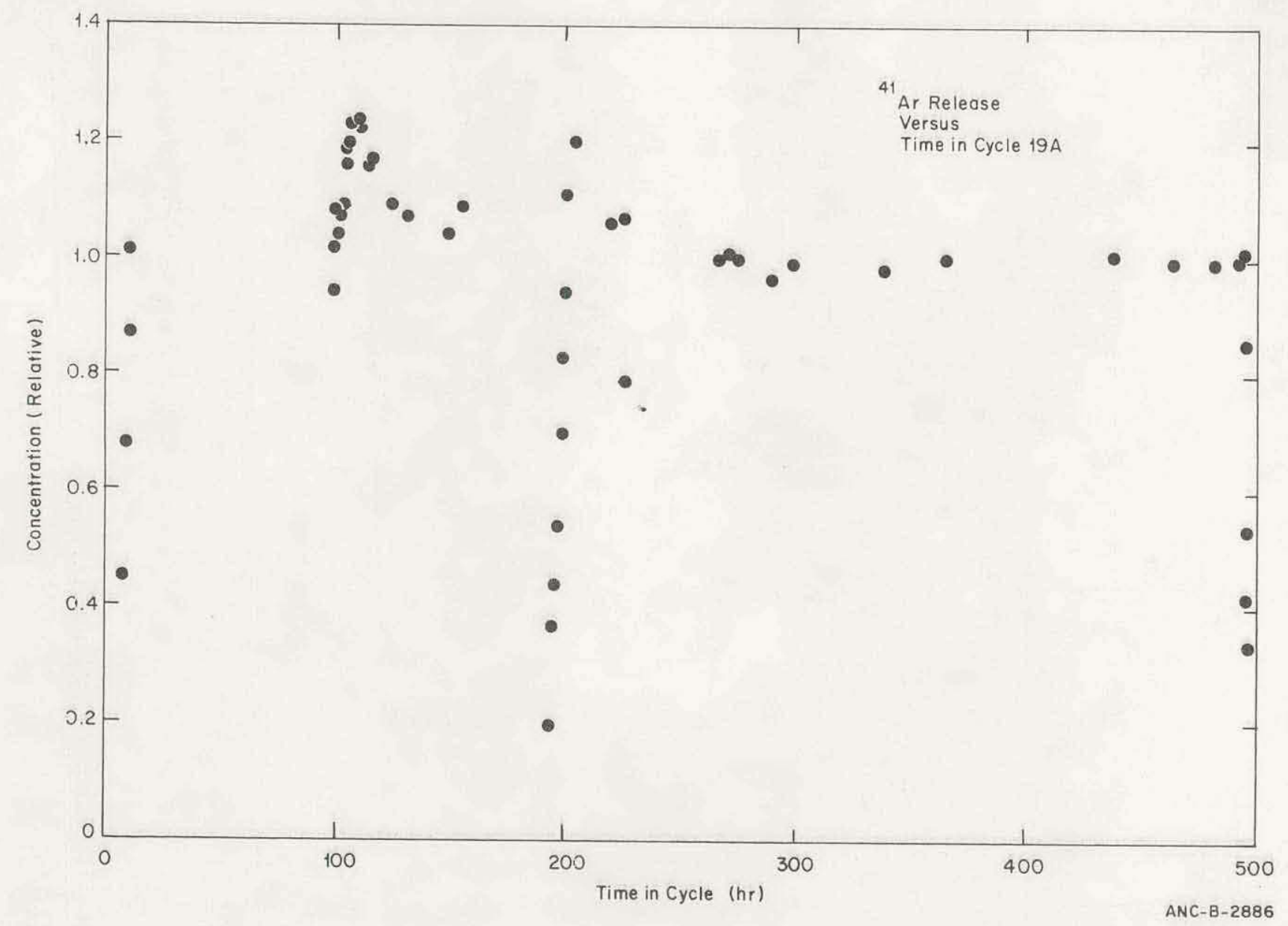

Figure 4. Release of ${ }^{41} \mathrm{Ar}$ during ATR cycle $19 \mathrm{~A} .{ }^{41} \mathrm{Ar}$ is not a fission product but is produced by neutron activation. 


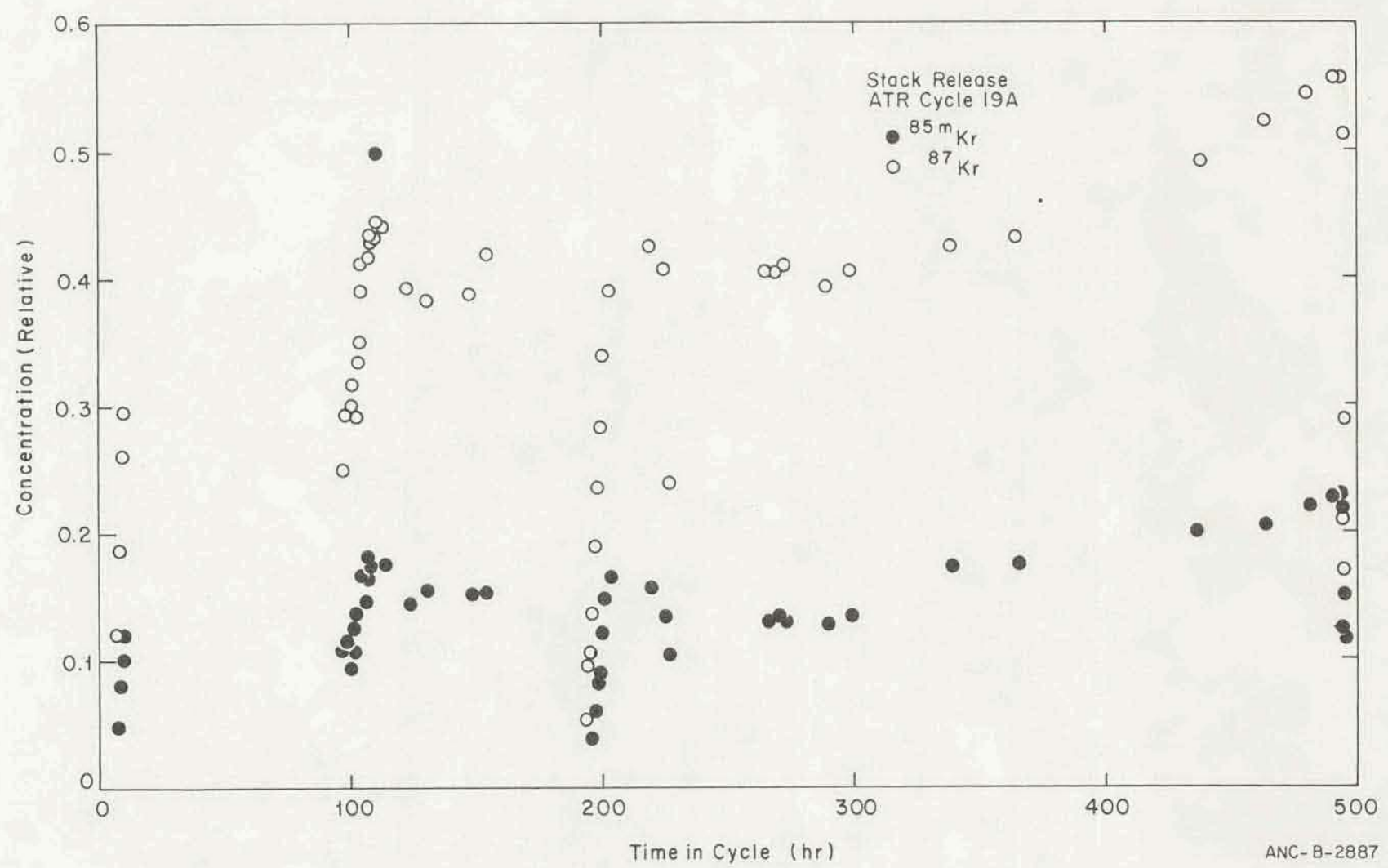

Figure 5. Release of $85 \mathrm{~m}_{\mathrm{Kr}}$ and ${ }^{87} \mathrm{Kr}$ during ATR cycle 19A. 


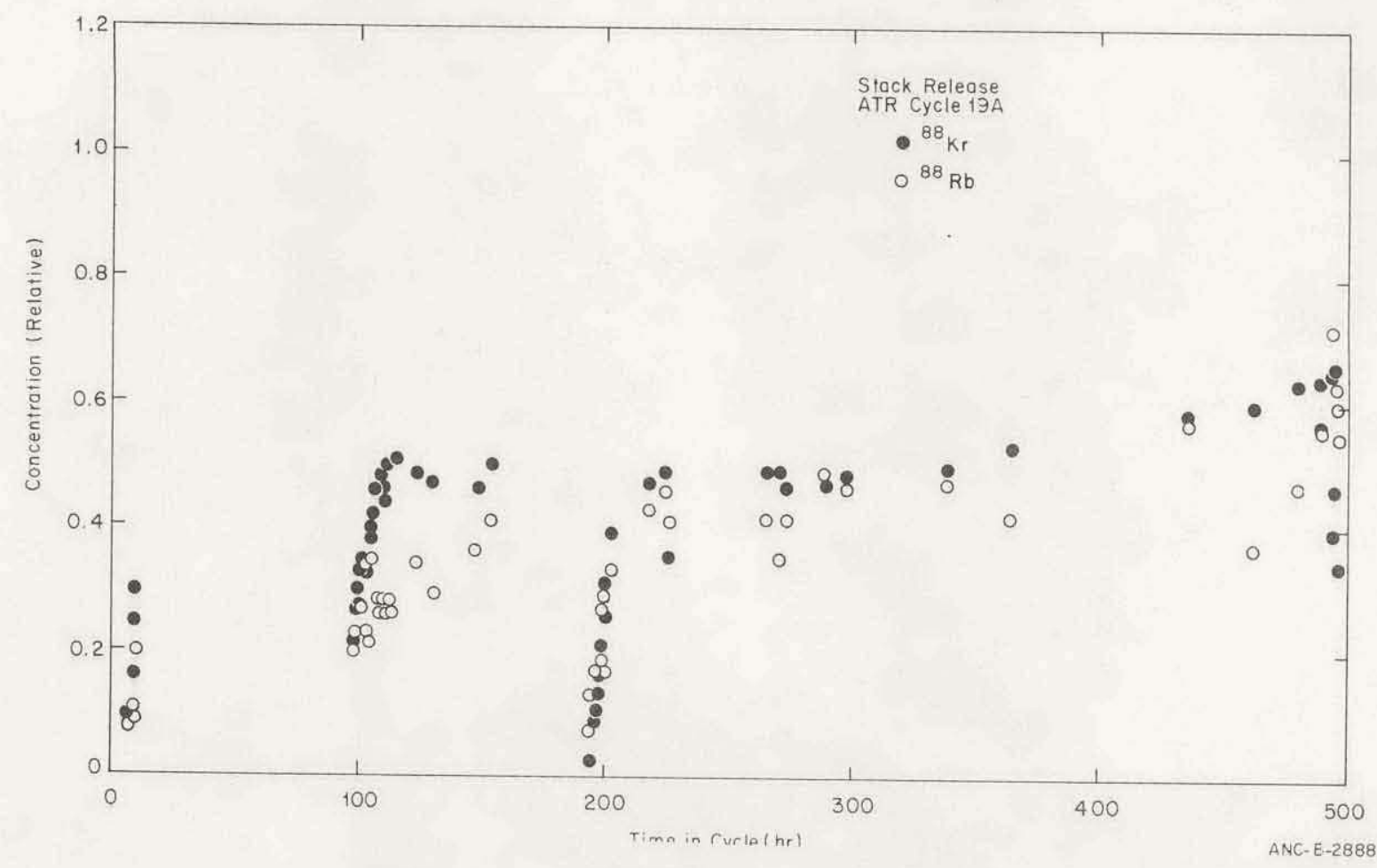

Figure 5. Release of ${ }^{38} \mathrm{Kr}$ and ${ }^{88} \mathrm{Rb}$ during ATR cycle $19 \mathrm{~A} .{ }^{88} \mathrm{Kr}$ and ${ }^{88} \mathrm{Rb}$ are both fission products. 


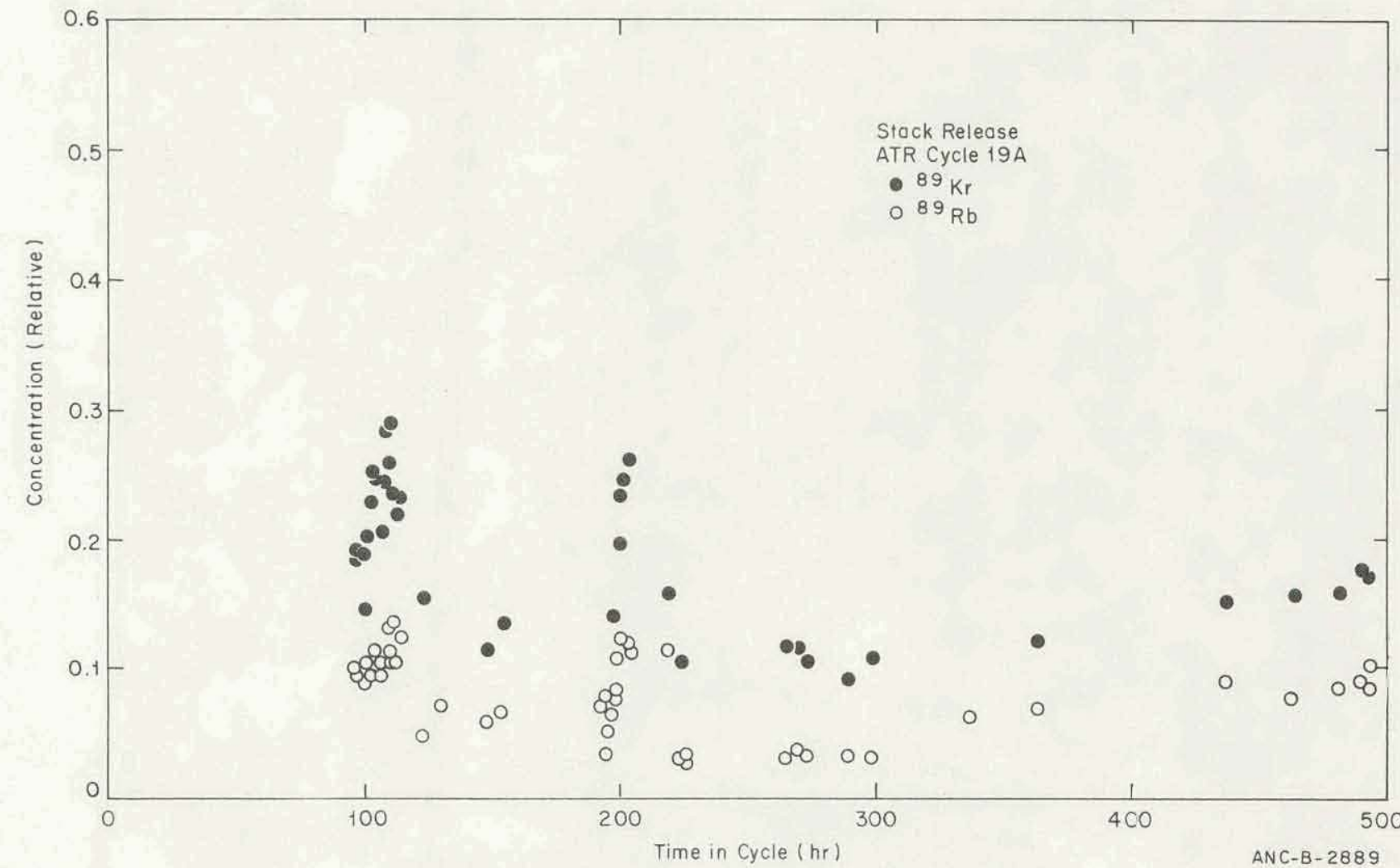

Figure 7. Release of ${ }^{89} \mathrm{Kr}$ and ${ }^{89} \mathrm{Rb}$ during ATR cycle $19 \mathrm{~A} .{ }^{89} \mathrm{Kr}$ and ${ }^{89} \mathrm{Rb}$ are both fission products. 


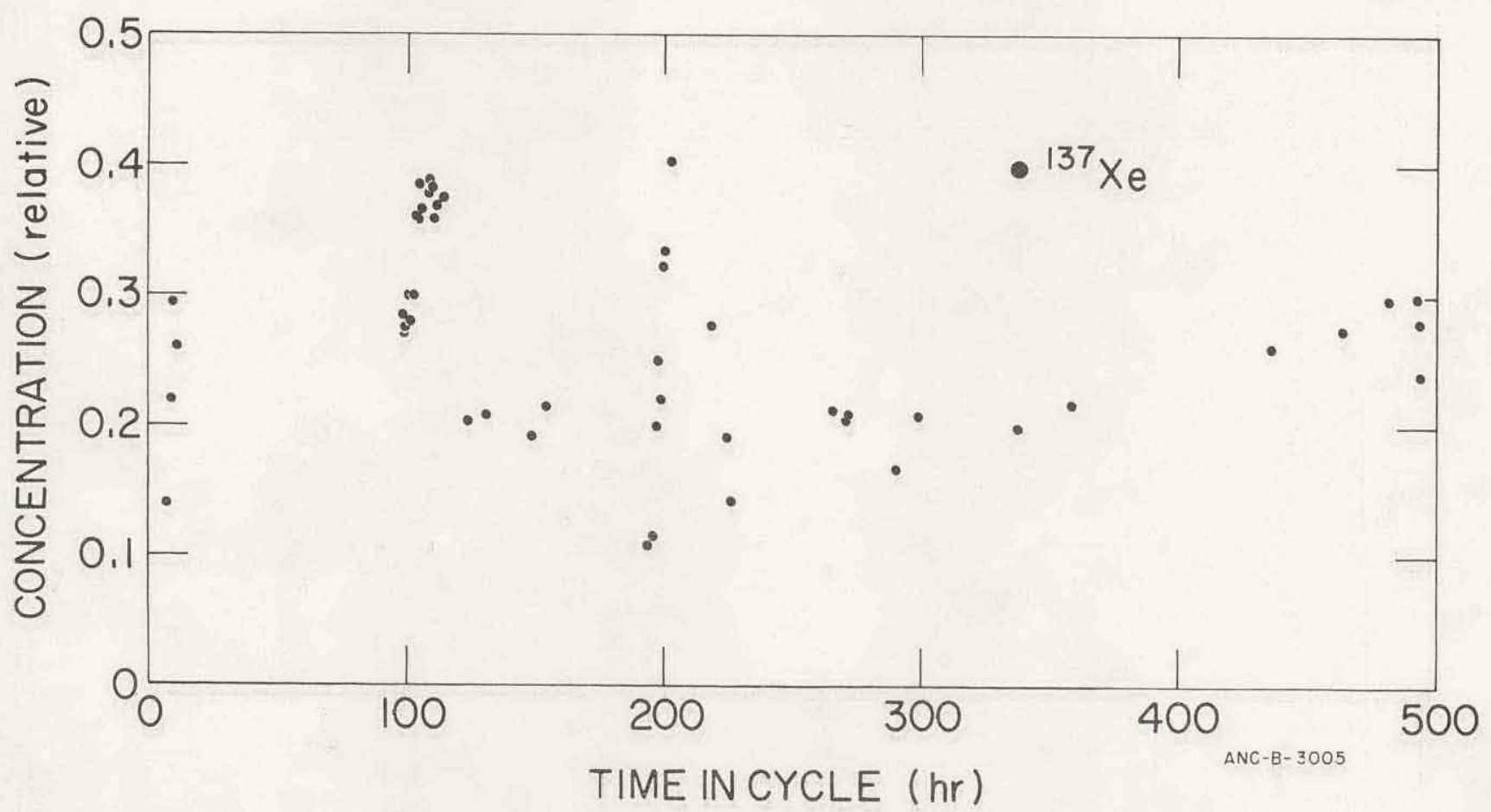

Figure 8. Release of ${ }^{137}$ Xe during ATR cycle 19A. ${ }^{137}$ Xe is a fission product. All ${ }^{137}$ Xe released ultimately becomes environmental ${ }^{137} \mathrm{Cs}$. 


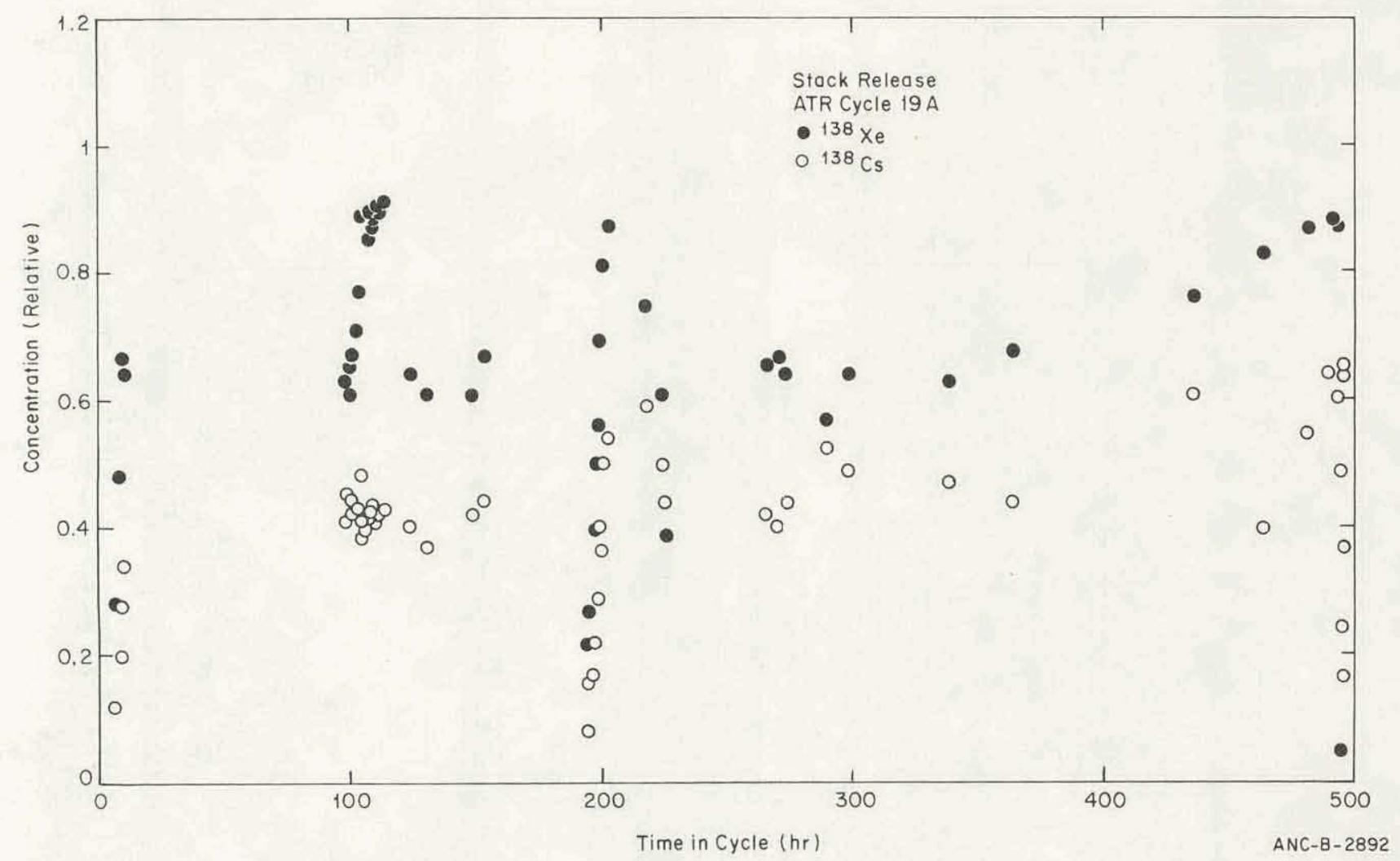

Figure 9. Release of ${ }^{138} \mathrm{Xe}$ and ${ }^{138} \mathrm{Cs}$ during ATR cycle $19 \mathrm{~A} .{ }^{138} \mathrm{Xe}$ and ${ }^{138} \mathrm{Cs}$ are both fission products. 
